\title{
Aspectos conceituais da regulação dos serviços de água e esgoto no Brasil
}

\section{Conceptual aspects of the regulation of water and sewage services in Brazil}

\author{
Alceu de Castro Galvão Junior \\ Engenheiro Civil. Mestre em Hidráulica e Saneamento pela Escola de Engenharia de São Carlos da Universidade de São Paulo (EESC/USP). Doutor em \\ Saúde Pública pela USP. Analista de Regulação da Agência Reguladora de Serviços Públicos do Estado do Ceará (Arce) \\ Wanderley da Silva Paganini \\ Engenheiro Civil. Doutor em Saúde Pública pela USP. Professor-associado da Faculdade de Saúde Pública da USP (FSP/USP). Livre-docente em \\ Saneamento Básico e Ambiental pela FSP/USP. Superintendente de Gestão Ambiental da Companhia de Saneamento Básico de São Paulo (Sabesp)
}

\section{Resumo}

Objetiva-se, aqui, apresentar os aspectos conceituais da regulação da prestação dos serviços de água e esgoto no Brasil e analisar de forma comparativa essa regulação com a de outros setores da infraestrutura. O estudo parte do pressuposto da regulação como intervenção do Estado voltada para a eficiência e a equidade, e apresenta os fundamentos teóricos que justificam essa regulação de forma contextualizada às características do setor de água e esgoto. Mediante análise comparativa com outros setores de infraestrutura de redes, concluí-se que, em função das características físicas, econômicas e institucionais do setor de água e esgoto, será bastante complexo o estabelecimento efetivo dessa atividade conforme os princípios da lei n 11.445/2007.

Palavras-chave: regulação; serviços públicos; saneamento básico; água e esgoto.

\section{Abstract}

The objective of this paper is to present the conceptual aspects of the regulation of water and sewage services in Brazil and to perform a comparative analysis of this regulation to the other sectors of the infrastructure. This study is based on the assumption of regulation as an intervention of the State turned to the efficiency and fairness, and presents the theoretical foundations to justify this regulation in the context of the characteristics of water and sewage sector. By comparison with other sectors of infrastructure networks, it has been concluded that depending on the physical, economic and institutional characteristics of water and sewage sector, this activity is quite complex to be effectively established according to the principles of law 11.445/2007.

Keywords: regulation; public services; basic sanitation; water and sewage.

\section{Introdução}

O acesso aos serviços de saneamento básico é condição fundamental para a sobrevivência e dignidade humana. O déficit em saneamento básico traz consequências graves em termos de saúde pública, meio ambiente e cidadania (HUTTON; HALLER, 2004; TEIXEIRA; PUNGIRUM, 2005).

De acordo com o relatório mundial de saúde da Organização Mundial da Saúde (OMS), estima-se que em 2007 existiam cerca de 1,1 bilhões de pessoas sem acesso à água segura e 2,6 bilhões sem saneamento adequado (ORGANIZAÇÃO MUNDIAL DA SAÚDE, 2007). Isso contribui diariamente para a morte de 4.500 crianças no mundo devido a doenças relacionadas com a falta de saneamento perfeitamente evitáveis, como a diarreia (ORGANIZAÇÃO MUNDIAL DA SAÚDE, 2007).

No Brasil, o déficit do setor de saneamento básico é elevado, sobretudo no que se refere ao esgotamento sanitário, com maior carência nas áreas periféricas dos centros urbanos e nas zonas rurais, onde se concentra a população mais pobre.

Diversos são os fatores responsáveis pelo déficit dos serviços de água e esgoto no país. Dentre eles, podem ser mencionadas a fragmentação de políticas públicas e a carência de instrumentos de regulamentação e regulação (NASCIMENTO; HELLER, 2005) e insuficiência e má aplicação de recursos públicos. De fato, desde o final 
dos anos 1980, com a extinção do Plano Nacional de Saneamento (Planasa), o país não dispõe de política setorial ${ }^{1}$ consistente, apesar dos esforços do governo federal mediante a criação do Ministério das Cidades e da Secretaria Nacional de Saneamento a partir de 2003. O principal impasse para o estabelecimento dessa política deve-se à interpretação da Constituição Federal quanto à titularidade dos serviços nos sistemas integrados e nas regiões metropolitanas, cuja decisão encontra-se sob análise do Supremo Tribunal Federal².

Somente no início de 2007 foi promulgada a lei n 11.445/2007, que estabelece as diretrizes nacionais para o saneamento básico. A lei definiu instrumentos e regras para o planejamento, a fiscalização, a prestação e a regulação dos serviços, tendo sido estabelecido o controle social sobre todas essas funções. Essa regulação deve ser realizada com independência, definida como autonomia administrativa, orçamentária e financeira da entidade reguladora, além de transparência, tecnicidade, celeridade e objetividade das decisões.

$\mathrm{Na}$ busca pela universalização, a regulação pode exercer vários papéis. Um deles é fazer cumprir, por meio das políticas regulatórias, as macrodefinições estabelecidas nas políticas públicas setoriais decididas no âmbito dos poderes executivo e legislativo. Outro papel seria desenvolver mecanismos que incentivem a eficiência das empresas prestadoras de serviço, pois, desse modo, mais recursos poderão ser canalizados para a expansão da infraestrutura. Além disso, a regulação proporciona um ambiente mais estável para realização de investimentos públicos e privados no setor. Outro aspecto relevante na discussão sobre regulação e universalização dos serviços de água e esgoto é a escassez de pesquisas na área institucional, fundamental como contribuição para a solução dos problemas do déficit de atendimento. A lacuna no campo do conhecimento das questões institucionais é evidente, até porque a regulação esteve ausente da pauta da agenda setorial nas três últimas décadas. Efetivamente, no campo da pesquisa acerca do saneamento básico, somente as questões tecnológicas têm ocupado espaço com muitos avanços ocorridos particularmente nas áreas de tratamento de água e de esgotos. Essa discussão, quando realizada de forma comparativa a outros setores de infraestrutura de redes mais maduros institucionalmente do que o setor de saneamento básico, facilita a compreensão dos desafios impostos a esse setor.

Inicialmente, a regulação da prestação de serviços públicos por meio de comissões foi discutida no âmbito das propostas para elaboração do Código das Águas nos anos 1930. Com o advento do Estado Novo e as subsequentes políticas desenvolvimentistas dos anos $1950 \mathrm{a}$ 1970, a provisão da infraestrutura ocorreu de forma direta pelo Estado, limitando a regulação, em geral, à expedição de normas e regulamentos pelo poder executivo, apesar dos avanços regulatórios no setor de energia elétrica. Esse modelo de regulação, no qual a propriedade estatal era a principal característica, vigorou no país até o final dos anos 1980.
Apenas em meados dos anos 1990, com os processos de privatização das áreas de energia e telefonia, a regulação, modelada no formato de agências reguladoras, foi efetivamente implantada no país. Naqueles setores onde a maior parte das concessões da prestação dos serviços permaneceu com empresas estatais, como o saneamento básico, a regulação alcançou até 2006 somente 13\% das concessões do país (GALVÃO JUNIOR; PAGANINI, 2006). A implantação da regulação no setor de água e esgoto apresenta enormes desafios. Não obstante o déficit de infraestrutura, há falta de capacidade políticoadministrativa dos entes federados, sobretudo dos municípios, para se prover regulação nos termos da lei no 11.445 (GALVÃO JUNIOR; TUROLLA; PAGANINI, 2008).

O ambiente institucional criado pela lei $n^{\circ} 11.445 / 2007$ aponta para a necessidade de estudos e pesquisas que estabeleçam diretrizes para a elaboração de políticas públicas setoriais e regulatórias, identifiquem formas de arranjos federativos de regulação, discutam desenhos de entes reguladores adaptados às realidades regionais $\mathrm{e}$, em especial, indiquem caminhos para a universalização dos serviços. Assim, o presente trabalho tem como objetivo apresentar os aspectos conceituais da regulação dos serviços de água e esgoto e analisar de forma comparativa essa atividade com as regulações de outros setores da infraestrutura.

Para equacionar os objetivos do estudo desenvolveu-se uma revisão teórica mediante análise do estado da arte da regulação e da legislação aplicada. Esses documentos foram interpretados e discutidos segundo os seguintes tópicos: teoria da regulação, propriedade estatal, formas de regulação, e características e regulação do setor de água e esgoto.

\section{Teoria da regulação}

As bases ideológicas da corrente majoritária do pensamento econômico moderno, denominada escola neoclássica, tiveram Adam Smith como um de seus principais precursores. Para Adam Smith, a felicidade das pessoas tinha origem na riqueza material e elas eram conduzidas por uma 'mão invisível' à promoção do bem-estar social, independentemente de suas vontades (HUNT, 2005). O bem-estar social seria atingido pelas forças econômicas que regulavam livremente a oferta e a demanda do mercado, sem qualquer interferência governamental. Assim, a função primordial do governo era garantir e promover a livre competição no mercado.

Na competição perfeita, haveria uma grande quantidade de ofertantes e de demandantes, homogeneidade dos produtos, ausência de restrições à entrada e à saída das firmas e todos teriam informações completas sobre as condições do mercado (PHILLIPS JUNIOR, 1993). Os defensores da escola neoclássica argumentavam que essas

\footnotetext{
${ }^{1}$ Compreendida como o conjunto de leis, mecanismos de investimentos, políticas regulatórias, entre outros.

${ }^{2} \mathrm{ADIN} n^{\circ} 1.842$, referente à ação impetrada pelo Partido Democrático Trabalhista contra o Governo e a Assembleia Legislativa do Estado do Rio de Janeiro; e a ADIN n 2.077, arguida pelo

Partido dos Trabalhadores contra a Assembleia Legislativa do Estado da Bahia.
} 
condições permitiriam que as empresas alcançassem a eficiência alocativa e produtiva e, consequentemente, o bem-estar social. A eficiência alocativa decorre da igualdade entre o preço oferecido no mercado e o custo marginal da firma para produzir a última unidade do produto ou serviço (FARINA; AZEVEDO; PICCHETTI, 1997). Já a eficiência produtiva é dividida em estática e dinâmica. Na eficiência produtiva estática, o custo total de produção ocorre ao menor valor possível, enquanto na dinâmica, são adotadas tecnologias mais avançadas para a produção de novos produtos e melhoria nos processos (FARINA; AZEVEDO; PICCHETTI, 1997)

Contudo, as sucessivas crises do capitalismo durante os séculos 18, 19 e início do século 20 demonstraram que os pressupostos da livre concorrência eram inconsistentes e não representavam a realidade econômica. Esses problemas foram denominados falhas de mercado e impossibilitavam o alcance de suas condições ótimas. Dessas falhas, as principais são o poder de mercado, também designado poder do monopólio, os bens públicos e as externalidades. Além disso, a evolução da teoria econômica agregou a assimetria de informações como falha determinante para o funcionamento dos mercados.

O monopólio se caracteriza pela atuação de uma ou poucas empresas de forma exclusiva em uma atividade econômica. Especificamente em relação aos serviços públicos, como abastecimento de água e distribuição de energia elétrica, nos quais é inviável a atuação de mais de uma empresa em um dado mercado, o monopólio é denominado natural. A existência de monopólios naturais se dá, sobretudo, em virtude da existência de economias de escala e/ou de escopo presentes na maioria dos serviços públicos de infraestrutura.

As economias de escala decorrem da existência de elevados custos fixos na produção de um bem, independentemente da quantidade produzida (PINHEIRO; SADDI, 2005). Contudo, nas economias de escopo, a produção de mais de um bem ou serviço apresenta custos comuns quando realizados por uma só empresa (PINHEIRO; SADDI, 2005). Este é o caso das empresas de saneamento básico que, para executar serviços de natureza diversa, produção e distribuição de água tratada, coleta e tratamento dos esgotos compartilham estruturas operacionais, como apoio administrativo, atendimento ao usuário, entre outros.

Como nos monopólios naturais dos serviços de utilidade pública a demanda é inelástica e não há ameaça de competição, as empresas monopolistas não oferecem incentivos para reduzir custos e melhorar a eficiência (JOURAVLEV, 2001A). Dessa forma, as vantagens econômicas de se ter uma única empresa que produz bens e serviços são desperdiçadas em decorrência do aumento dos preços e da diminuição da qualidade dos serviços, o que resulta na apropriação de lucros excessivos pelos monopólios.

Quando a produção de bens e serviços causa impactos positivos e negativos a terceiros não relacionados à atividade econômica, tem-se a ocorrência de externalidades. Em geral, o custo da externalidade não é internalizado pela empresa e, dependendo do impacto, o custo social é maior do que o custo privado do bem ou serviço. Nessa situação, as empresas atuam de forma oportunista, aumentando a produção, pois parte do custo de produção é transferido para a sociedade (VARGAS; LEME; LIMA, 2002). Das externalidades ambientais, as de caráter negativo são as mais frequentes. Ao emitir gases em quantidade e concentração não admissíveis, uma indústria polui o meio ambiente, e ocasiona, por exemplo, doenças respiratórias na população circunvizinha, entre outros problemas. Como resultado, as despesas do tratamento dos doentes e de todos os impactos econômicos e não econômicos são custeadas pela própria sociedade, já que a empresa não realizou o tratamento dos efluentes gasosos e, por conseguinte, não incorporou esses custos em seu produto.

Diante das características dos bens e serviços públicos, como a não exclusividade e a não rivalidade, o mercado competitivo não se forma para a produção desses bens e serviços. $\mathrm{O}$ acesso aos sistemas de saúde e de educação são casos típicos, pois na ausência de prestadores privados ou na incapacidade do cidadão de custear o serviço, o Estado não pode se isentar de provê-lo de forma adequada e universal.

Por último, a ausência de informações sobre as reais condições do mercado não permite que os agentes econômicos, sejam eles produtores ou consumidores, tomem decisões perfeitas, consequentemente não levando à alocação eficiente dos recursos disponíveis. Por exemplo, as empresas usam informações sobre custos e qualidade de seus produtos de forma estratégica na determinação dos preços finais aos consumidores. Já esses, por distinguirem em geral apenas as características estéticas dos produtos, colocam-se em uma situação de hipossuficiência em relação aos produtores.

A intervenção do Estado se dá por meio da regulação ou pela propriedade estatal. Na Figura 1 apresentam-se esquematicamente os pressupostos neoclássicos para intervenção do Estado na economia.

Diversos autores conceituam a regulação como a restrição das decisões dos agentes econômicos por meio do poder de coerção do Estado (VISCUSI; HARRINGTON; VERNON, 2005; PINHEIRO; SADDI, 2005). Essa visão focada no controle das atividades econômicas limita o escopo da regulação às transações de mercado. Por outro lado, o entendimento dos juristas se contrapõe à visão econômica em dois aspectos fundamentais. Primeiro no que diz respeito à abrangência: a regulação é definida como a atuação do Estado não só na ordem econômica, mas também na ordem social com a finalidade de proteger o interesse público (DI PIETRO, 2004). Segundo, a autoridade do Estado passa a ser exercida de forma a mediar os conflitos e interesses envolvidos ao invés do uso do poder coercitivo (NAVES, 2004; MARQUES NETO, 2005).

No presente trabalho, o conceito de regulação é entendido como a intervenção do Estado nas ordens econômica e social com a finalidade de se alcançarem eficiência e equidade, traduzidas como universalização na provisão de bens e serviços públicos de natureza essencial por parte de prestadores de serviço estatais e privados. No Brasil, a regulação dos serviços públicos por meio de agências 


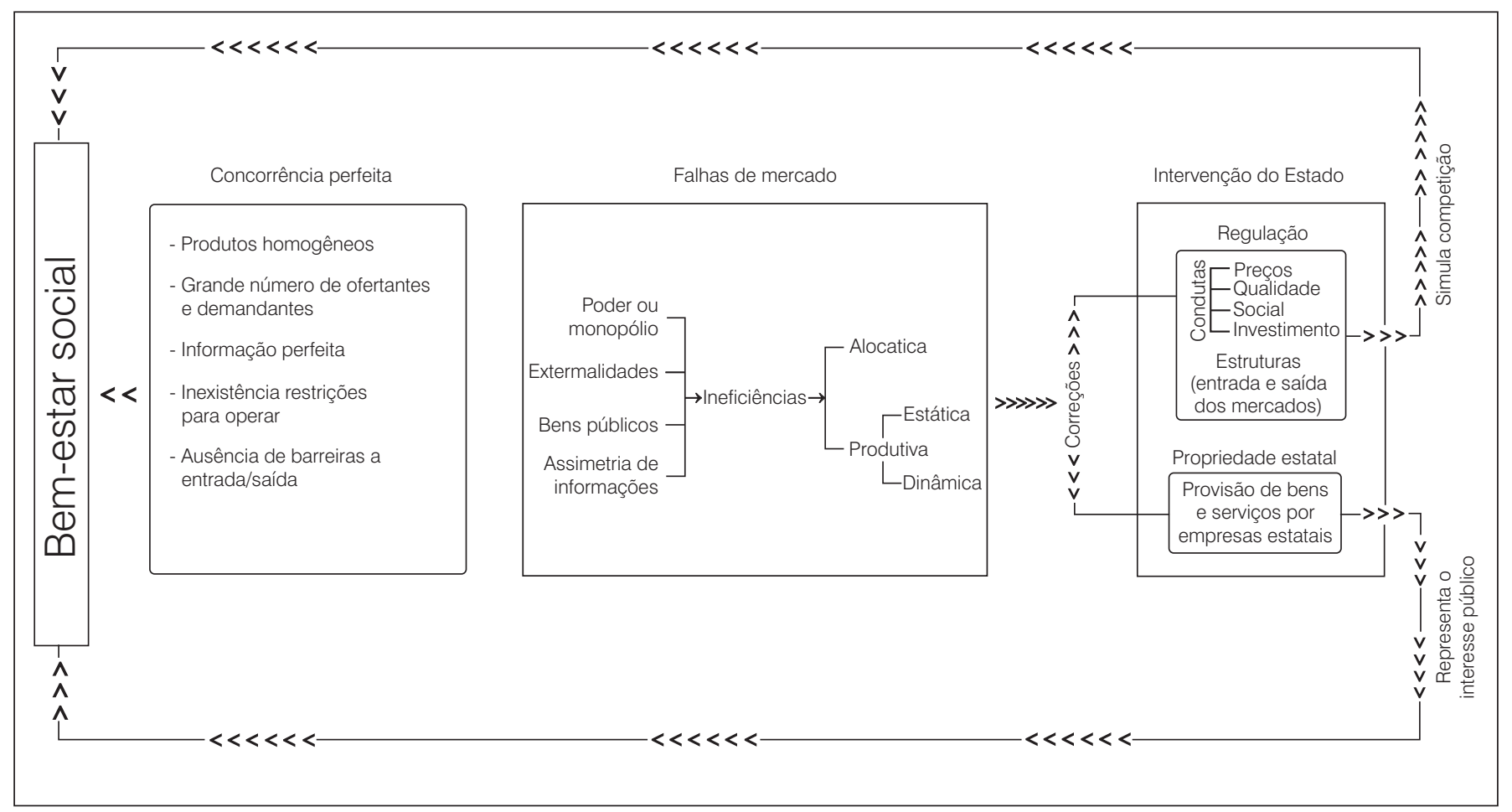

Figura 1 - Pressupostos para intervenção do Estado na economia

reguladoras ocorreu somente em meados dos anos 1990 no processo de reforma do Estado, no qual setores da infraestrutura tiveram seus controles acionários abertos à participação da iniciativa privada. Nesse processo de reforma, a lógica central era a mudança do perfil do Estado brasileiro, de produtor de bens e serviços para regulador de serviços públicos concedidos à iniciativa privada. Esse processo ocorreu simultaneamente em vários países da América Latina sob um arcabouço ideológico neoconservador (SILVA, 2002), incentivado pelas instituições multilaterais como o Banco Mundial e o Fundo Monetário Internacional (FMI).

\section{Propriedade estatal}

Conforme abordado, a teoria econômica preconiza como correção para as falhas de mercado, a propriedade estatal ou a regulação. $\mathrm{Na}$ propriedade estatal, o interesse público estaria representado pelo Estado, que seria responsável pela provisão direta de bens e serviços. Nessas circunstâncias, o objeto da atividade econômica seria a maximização do bem-estar social. Além da correção das falhas de mercado, a provisão estatal foi utilizada como instrumento de desenvolvimento econômico, principalmente na Europa e na América Latina, onde a atividade econômica estatal avançou até mesmo sobre áreas passíveis de competição, como mineração, siderurgia, aviação, entre outros.

No Brasil, apesar de o modelo de provisão estatal ter sido estimulado como instrumento de desenvolvimento nacional a partir dos anos 1950, foi somente após a edição do Decreto-lei n 200 em 1967, que criou empresas públicas e de economia mista, que o modelo se tornou determinante na execução das políticas públicas (SILVA, 2004). Nesse período, foram estabelecidas empresas estatais para provisão de serviços públicos por rede nas áreas de telefonia, energia elétrica e saneamento básico (concessionárias estaduais de saneamento básico). No país, a despeito de essas empresas terem alcançado enorme avanço, sobretudo em termos de expansão das redes, a regulação, caso existente à época, poderia ter alavancado os indicadores de cobertura para níveis próximos à universalização.

Não obstante a propriedade estatal ser considerada uma alternativa à regulação, Marques Neto (2005) apresenta vários argumentos para justificar a regulação de empresas estatais: os interesses das empresas e de seus controladores não necessariamente representam o interesse público; não existe divisão de papéis entre regulado e regulador; e, por ser a regulação uma atividade tipicamente estatal, há incompatibilidade com o regime jurídico das empresas estatais ${ }^{3}$.

A regulação de empresas estatais também constitui um resgate da cidadania, pois a mistura de papéis entre operador e titular dos serviços alijou a sociedade do controle dos serviços públicos (NÚCLEO DE PESQUISAS EM INFORMAÇÕES URBANAS, 1995). Com isso, surgiram consequências para a prestação dos serviços, pois na ausência de cobrança por expansão e por melhoria da qualidade, houve transferência parcial das ineficiências à população por meio de tarifas elevadas.

${ }^{3}$ As empresas estatais, cuja maioria é representada por sociedades de economia mista, são consideradas pela legislação (Decreto-lei no 900, de 1969) como entidades dotadas de personalidade jurídica de direito privado. 
A provisão dos serviços por empresas estatais no país ainda é majoritária em setores da infraestrutura, como o petróleo e o saneamento básico. Não obstante reconhecer que ambas as participações cumprem papéis fundamentais e diferentes na provisão da infraestrutura brasileira, o que se deve garantir, independentemente da propriedade dos ativos, seja pública ou privada, é a regulação dos serviços como forma de preservar o interesse público.

\section{Formas de regulação}

As empresas monopolistas de serviços públicos apresentam dois tipos de regulação: estrutural e de condutas. A regulação estrutural aborda as condições de entrada e de saída das firmas nos setores regulados e as medidas para separação vertical de segmentos da prestação dos serviços (PINHEIRO; SADDI, 2005). Na separação vertical, o processo de produção de bens e serviços é segmentado em várias etapas, o que permite a atuação de várias empresas nas diferentes fases da cadeia produtiva (JOURAVLEV, 2001A). Já a de condutas regula o comportamento das empresas dentro do mercado e engloba preços, qualidade e investimentos (JOURAVLEV, 2001B)

Como cada setor da infraestrutura apresenta estágios diferentes de desenvolvimento tecnológico e características específicas quanto ao nível de competição em alguns segmentos da prestação dos serviços, os papéis da regulação estrutural e de condutas assumem configurações variadas para cada setor. Por exemplo, na energia, a cadeia produtiva é dividida em geração, transmissão e distribuição. Essa condição de desverticalização permite que na geração várias empresas, inclusive com diferentes matrizes energéticas, concorram para ofertar energia aos distribuidores. Assim, nessa área, assume um papel relevante a regulação estrutural que define as condições de participação das firmas no mercado de produção de energia. No entanto, o segmento final desse setor, a distribuição, é monopólio natural, onde a regulação de condutas é necessária para simular competição e corrigir falhas de mercado.

Ao mesmo tempo, no saneamento básico, as características do setor não permitem competição, seja pela inviabilidade econômica da desverticalização da prestação dos serviços, seja pela falta de mudanças no padrão tecnológico. Há também outros fatores que dificultam a desagregação do saneamento básico, como a geração de economias de escopo em função da verticalização do setor e a dificuldade de tarifação das diversas etapas da produção (JOURAVLEV, 2004). A Figura 2 apresenta de forma esquemática as configurações dos setores de energia e saneamento básico e as possibilidades de competição em cada área.

Já para o setor de telecomunicações, a tecnologia viabiliza a competição das empresas para operação dos serviços. Nesse caso, a concorrência originou-se da dinâmica da evolução tecnológica e impõe participação efetiva da regulação estrutural nas condições de acesso das empresas ao mercado.

De acordo com Jouravlev (2003), a diferença entre o saneamento básico e os setores de telecomunicações e energia, é que a regulação deve se estender a todos os segmentos da prestação dos serviços, em virtude da dificuldade de competição nesses segmentos.

Quanto à regulação de condutas, a fixação de preços é a mais relevante, pois interfere diretamente nas condições econômico-financeiras dos serviços regulados. No Quadro 1, constam as características dos principais métodos de regulação de preços, taxa de retorno e teto de preços.

Conforme observado no Quadro 1, independentemente do método adotado para regulação de preços, as atividades necessárias para determinação de custos e valoração de ativos são complexas e exigem elevada expertise dos reguladores. No Brasil, o principal mecanismo de precificação utilizado é o da taxa de retorno ${ }^{4}$, adotado desde a edição do Decreto no 24.643, de 10 de julho de 1934, que instituiu o Código das Águas (BRASIL, 1934). Com efeito, a principal crítica a esse método diz respeito à possibilidade de sobreinvestimento, o que geraria desincentivos para a busca de eficiência pelos prestadores de serviços.

Já a regulação da qualidade tem como objetivo fixar condições e parâmetros para a qualidade dos produtos e serviços prestados e, também, verificar o cumprimento dessas disposições. Especificamente em relação aos setores da infraestrutura, o Quadro 2 identifica alguns aspectos importantes para a regulação da qualidade dos serviços públicos de infraestrutura.

Conforme observado nesse quadro, a regulação da qualidade exige mecanismos diretos e indiretos para acompanhamento dos parâmetros e indicadores regulados, que demandam recursos humanos e custos elevados.

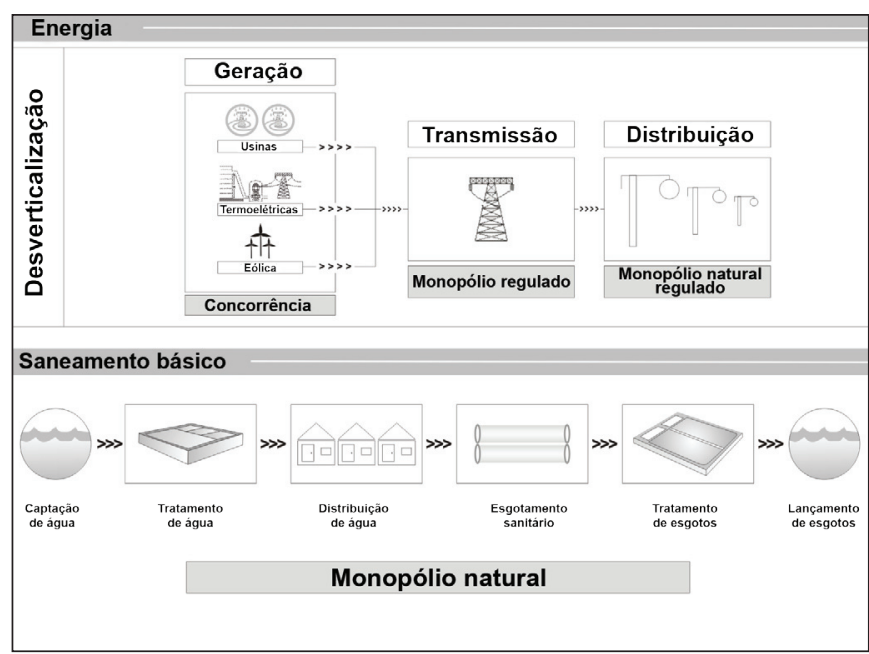

Figura 2 - Configurações dos setores de energia e saneamento básico 
Quadro 1 - Características dos principais métodos de regulação de preços

\begin{tabular}{|c|c|c|}
\hline Características & Taxa de retorno (rate of return) & Teto de preço (price cap) \\
\hline Cálculo & $\begin{array}{l}\mathrm{R}=\mathrm{O}+\mathrm{XA} \\
\text { Onde: } \\
\mathrm{R}: \text { receitas requeridas; } \\
\mathrm{O} \text { : custos operacionais e de depreciação; } \\
\mathrm{A} \text { : base de ativos a ser remunerada; } \\
\mathrm{x} \text { : taxa de retorno; } \\
\mathrm{O} \text { valor total das tarifas cobradas deve ser igual a } \mathrm{R}\end{array}$ & $\begin{array}{l}\mathrm{P}=\mathrm{RPI}-\mathrm{X} \\
\text { Onde: } \\
\mathrm{P}: \text { preço } \\
\text { RPI: índice de preços no varejo } \\
\mathrm{X} \text { : fator de produtividade }\end{array}$ \\
\hline Procedimento & $\begin{array}{l}\text { 1. Empresa apresenta custos (operacionais e de depre- } \\
\text { ciação) e base de ativos a ser remunerada; } \\
\text { 2. Regulador avalia/revisa custos }(O) \text { e valor de ativos } \\
\text { (A), e define taxa de remuneração }(x) \text {. Os custos aceitos } \\
\text { pelo regulador e a remuneração dos ativos compõem as } \\
\text { receitas requeridas; } \\
\text { 3. Define-se o nível de preços que cubra as receitas } \\
\text { requeridas a um lucro zero }\end{array}$ & $\begin{array}{l}\text { 1. Regulador fixa limite máximo de preços de um bem ou } \\
\text { serviço ou de um conjunto destes; } \\
2 \text {. Ao longo do intervalo regulatório, os preços são } \\
\text { reajustados pelo índice de inflação e reduzidos por um } \\
\text { fator de produtividade; } \\
\text { 3. Ao final do período regulatório, é fixado novo limite } \\
\text { com os ganhos de eficiência distribuídos entre prestador } \\
\text { e usuários }\end{array}$ \\
\hline Base dos custos & Histórica (ex-ante), ajustada mediante inflação projetada. & $\begin{array}{l}\text { Prospectiva (ex-post) fundamentada na operação de } \\
\text { uma empresa eficiente }\end{array}$ \\
\hline Intervalo regulatório & $\begin{array}{l}\text { Breve e endógeno, ou seja, depende da conduta da } \\
\text { empresa no período }\end{array}$ & $\begin{array}{l}\text { Prolongado e exógeno, suficiente para que a empresa } \\
\text { promova redução de custos e inovações na produção }\end{array}$ \\
\hline Grau de intervenção regulatória & Acompanhamento contínuo do desempenho operacional & $\begin{array}{l}\text { Controle no recebimento do serviço com base em um } \\
\text { conjunto de parâmetros de qualidade }\end{array}$ \\
\hline Grau de liberdade da empresa & $\begin{array}{l}\text { Pequeno, pois alterações de preços necessitam de } \\
\text { aprovação do regulador }\end{array}$ & $\begin{array}{l}\text { Grande, pois o regulador fixa um teto de preços, po- } \\
\text { dendo a empresa cobrar tarifas inferiores a este }\end{array}$ \\
\hline Origem & Estados Unidos & Inglaterra \\
\hline Desvantagens & $\begin{array}{l}\text { Sobreinvestimento, pois o aumento dos lucros é função } \\
\text { da ampliação da base de ativos; } \\
\text { Incentivos fracos para ganhos de eficiência e melhorias } \\
\text { tecnológicas; } \\
\text { Assimetria de informações dificulta a correta identifica- } \\
\text { ção dos custos incorridos na prestação dos serviços }\end{array}$ & $\begin{array}{l}\text { Pode gerar subinvestimento; } \\
\text { Outorga lucros excessivos às empresas; } \\
\text { Há redução na qualidade dos serviços prestados com o } \\
\text { objetivo de diminuir custos e aumentar lucros }\end{array}$ \\
\hline
\end{tabular}

Fonte: elaborado pelos autores com base em Farina, Azevedo e Picchetti (1997), Jouravlev (2001B), Moita (2000), Phillips (1993), Pinheiro e Saddi (2005), Silva (2004), Viscusi, Harrington e Vernon (2005)

Quadro 2 - Regulação da qualidade de serviços públicos de infraestrutura

\begin{tabular}{|c|c|}
\hline Infraestrutura & Exemplos de parâmetros regulados \\
\hline Energia elétrica & $\begin{array}{l}\text { - Duração equivalente de interrupção por } \\
\text { unidade consumidora; } \\
\text { - Duração de interrupção individual por } \\
\text { unidade consumidora ou por ponto de } \\
\text { conexão; } \\
\text { Duração máxima de interrupção contínua } \\
\text { por unidade consumidora ou por ponto de } \\
\text { conexão }\end{array}$ \\
\hline Saneamento básico & $\begin{array}{l}\text { - Pressão dinâmica disponível na rede de } \\
\text { distribuição; } \\
\text { Pressão estática máxima na rede de dis- } \\
\text { tribuição; } \\
\text { - Parâmetros físico-químicos (cor, turbidez, } \\
\text { pH, metais, etc.) e bacteriológicos da água } \\
\text { distribuída }\end{array}$ \\
\hline Telecomunicações & $\begin{array}{l}\text { - Quantidade de reparos de telefone de uso } \\
\text { - } \quad \text { Cháblico/100 TUPs; } \\
\text { mento da prestadora no período de maior } \\
\text { movimento; } \\
\text { - Solicitações de reparo, por cem acessos } \\
\text { em serviço por mês; } \\
\text { - Tempo de atendimento das solicitações de } \\
\text { reparo }\end{array}$ \\
\hline
\end{tabular}

Fonte: elaborado pelos autores com base em Agência Nacional de Telecomunicações (2003), Agência Nacional de Energia Elétrica (2000), Agência Reguladora de Serviços Públicos Delegados do Estado do Ceará (2001).
De acordo com Jouravlev (2001B), as regulações de preço e de qualidade são interdependentes, pois uma redução da qualidade equivale a um aumento de preços. Entretanto, essa abordagem não tem sido compreendida pelos reguladores, provavelmente em decorrência da complexidade da análise da regulação da qualidade com métodos de regulação de preços.

Para os serviços de infraestrutura, o formato de regulação depende da análise, entre outras, das seguintes variáveis: falhas de mercado, características do mercado regulado, ambiente político-institucional, propriedade dos ativos, titularidade dos serviços e capacidade administrativa do Estado para regular os serviços. Cada uma dessas variáveis apresenta possibilidades múltiplas, o que torna a definição do formato da regulação uma tarefa complexa. As Figuras 3 e 4 apresentam as principais variáveis e subvariáveis para a escolha da forma de regulação dos serviços públicos de telecomunicações e saneamento básico, respectivamente.

$\mathrm{Na}$ primeira situação (Figura 3) são apresentadas as principais variáveis que determinam a forma de regulação dos serviços de telecomunicações. Nesse setor, sobretudo em decorrência das características da titularidade dos serviços, da capacidade do Estado para regular e da existência do marco regulatório, o melhor formato de regulação é por agências. Apesar da vantagem do acompanhamento 


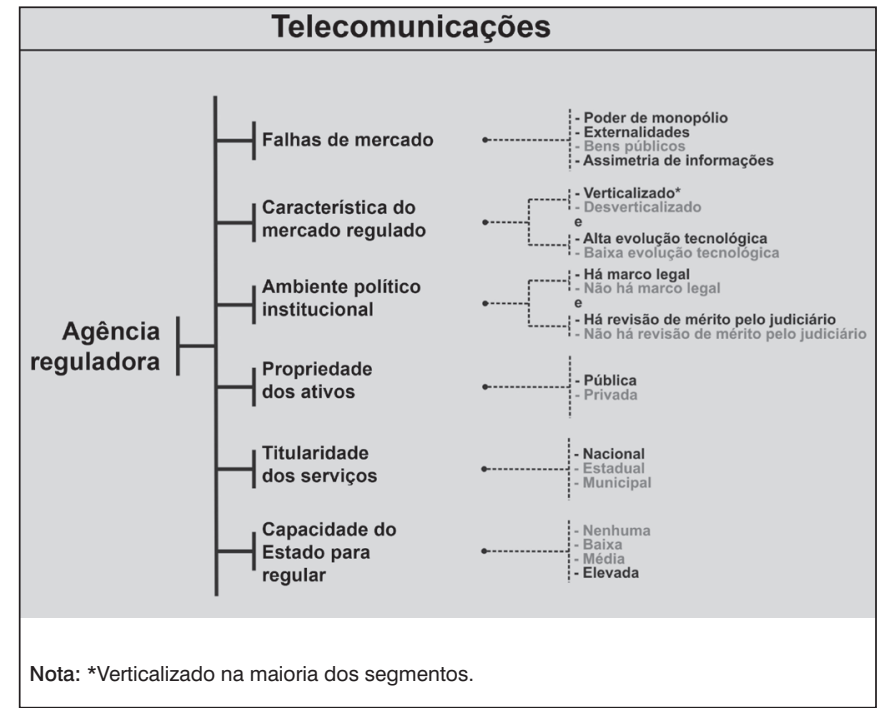

Figura 3 - Principais variáveis para definição da forma de regulação no setor de telecomunicações

permanente da prestação desses serviços por agência reguladora, seus custos de operação e manutenção são elevados.

Já no contexto do saneamento básico, mostrado na Figura 4, onde as falhas de mercado são mais evidentes, notadamente as externalidades e o poder de monopólio, a titularidade é fragmentada, e há falta de capacidade dos entes federados para regular os serviços, a regulação por contratos é provavelmente o melhor formato. Dessa forma, mesmo sem uma entidade reguladora, a presença de garantias legais permite que o titular dos serviços argua junto ao judiciário o cumprimento das obrigações contratuais. Entretanto, as desvantagens desse formato estão relacionadas à falta de acompanhamento contínuo das metas e obrigações contratuais, à rigidez contratual e à dependência do judiciário para solução de conflitos, o que pode retardar investimentos e a solução de problemas.

Dentro da regulação por agências, há ainda vários arranjos institucionais, como a formação de consórcios entre estados e municípios, ou entre municípios para regulação dos serviços, ou a delegação dessa atividade à agência reguladora de outro ente federado. Essas alternativas podem viabilizar a regulação em virtude da economicidade que a agregação de várias concessões proporciona à função reguladora.

Além disso, os formatos apresentados não são rígidos e admitem combinações entre diferentes formas de regulação, a exemplo de contrato com presença de agência reguladora. Assim, essas alternativas permitem que, mesmo sem capacidade para regular, titulares dos serviços compartilhem ou deleguem a regulação a outros entes públicos, proporcionando efetividade à atividade.

\section{Características e regulação do setor de água e esgoto}

As características do setor de água e esgoto, apresentadas no Quadro 3, conferem várias dimensões de análise a essa prestação de

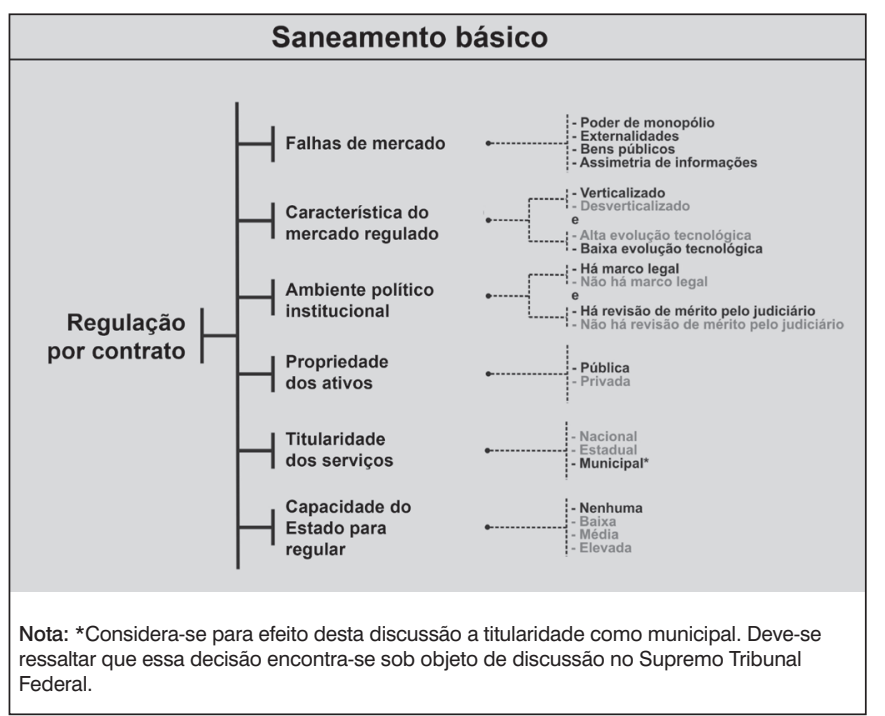

Figura 4 - Principais variáveis para definição da forma de regulação no setor de saneamento básico

serviços, além de justificar, de forma inequívoca, a necessidade de regulação setorial. Tais características apresentam importantes repercussões para a definição dos arranjos institucionais de gestão e de regulação da prestação dos serviços e, mais especificamente, para delimitar a forma de atuação dos reguladores.

A localização da infraestrutura de redes dificulta a verificação das condições de manutenção e operação, o que resulta no aumento da carga de fiscalização e de informação para os reguladores (JOURAVLEV, 2001B). Em virtude do caráter essencial dos serviços, a qualidade de seus produtos assume maior importância que em qualquer outro setor da infraestrutura de serviços públicos, obrigando o regulador a monitorá-la continuamente.

Devido à assimetria de informações, o regulador tende a focar sua atuação nas condutas mais facilmente observáveis do regulado (JOURAVLEV, 2003), como a qualidade da água distribuída e a pressão disponível na rede, cuja coleta de dados pode ser realizada diretamente pelo regulador. Esse comportamento pode restringir a abrangência da atividade, deixando em segundo plano questões centrais, como a verificação de custos e tarifas, sobre as quais os reguladores dependem de informações disponibilizadas pelos prestadores de serviço.

Outra repercussão importante decorre da existência de externalidades, cujos efeitos extrapolam os limites da atuação da regulação setorial e o escopo dos contratos de prestação dos serviços. Assim, as interfaces do setor com as áreas de saúde pública, meio ambiente, recursos hídricos e defesa do consumidor ampliam a complexidade e o volume de informações requeridos para a adequada regulação e exigem articulação intersetorial.

As características econômicas do setor, relativas ao elevado volume de investimentos e à especificidade dos ativos, podem gerar comportamento oportunista ex-post dos reguladores, como, por exemplo, 
Quadro 3 - Características do setor de saneamento e suas repercussões

\begin{tabular}{|c|c|c|}
\hline \multicolumn{2}{|c|}{ Características } & Repercussões \\
\hline \multirow{5}{*}{ 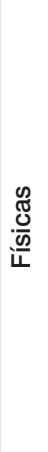 } & $\begin{array}{l}\text { Maioria dos ativos (redes de água e } \\
\text { esgoto) encontra-se enterrada }\end{array}$ & $\begin{array}{l}\text { Difícil determinação do estado de conservação; } \\
\text { Custo de manutenção elevado e complexidade para detecção de vazamentos nas tubulações }\end{array}$ \\
\hline & $\begin{array}{l}\text { Mudança lenta no padrão tec- } \\
\text { nológico }\end{array}$ & $\begin{array}{l}\text { Poucos ganhos de eficiência mediante avanços tecnológicos; } \\
\text { Ativos com vida útil prolongada }\end{array}$ \\
\hline & $\begin{array}{l}\text { Qualidade dos produtos de compl- } \\
\text { exa verificação pelo usuário }\end{array}$ & $\begin{array}{l}\text { Necessidade de estrutura adequada para monitoramento da qualidade de produtos e serviços oferta- } \\
\text { dos pelas concessionárias }\end{array}$ \\
\hline & $\begin{array}{l}\text { Redes integradas em aglomerados } \\
\text { urbanos }\end{array}$ & $\begin{array}{l}\text { Envolvimento de mais de um ente federado na gestão dos serviços; } \\
\text { Expansão da infraestrutura associada ao planejamento urbano }\end{array}$ \\
\hline & $\begin{array}{l}\text { Essencialidade no uso e consumo } \\
\text { dos produtos (água e esgoto) }\end{array}$ & $\begin{array}{l}\text { Atendimento independe da capacidade de pagamento do usuário; } \\
\text { Geração de externalidades positivas e negativas para a saúde pública, meio ambiente, recursos hídri- } \\
\text { cos, entre outros }\end{array}$ \\
\hline \multirow{6}{*}{ 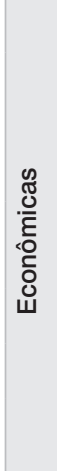 } & Custo fixo elevado & Pouca flexibilidade para etapalização dos investimentos \\
\hline & $\begin{array}{l}\text { Ativos específicos e de longa } \\
\text { maturação }\end{array}$ & $\begin{array}{l}\text { Monopólio natural; } \\
\text { Inexistência de usos alternativos e baixo valor de revenda; } \\
\text { Possibilidade remota de saída das concessionárias do mercado (não-contestável); } \\
\text { pouca atratividade para investimentos }\end{array}$ \\
\hline & Assimetria de informações & $\begin{array}{l}\text { Demais atores do setor dependem da informação técnica e econômico-financeira disponibilizada pelas } \\
\text { concessionárias }\end{array}$ \\
\hline & Demanda inelástica & Possibilidade de extração de rendas significativas pelo prestador de serviços (monopólio) \\
\hline & Economias de escala & Viabilidade da prestação dos serviços por uma única empresa (monopólio) \\
\hline & Economias de escopo & $\begin{array}{l}\text { Custos comuns na operação de serviços de água e esgoto e tratamento de esgotos, tornando mais } \\
\text { viável a prestação dos serviços por uma única empresa (monopólio) }\end{array}$ \\
\hline
\end{tabular}

Fonte: elaborado pelos autores com base em Farina, Azevedo e Picchetti (1997), Jouravlev (2001B), Núcleo de Pesquisas em Informações Urbanas (1995), Seroa da Motta e Moreira (2006), Turolla e Ohira (2006).

mudanças de regras tarifárias após a construção de obras e instalações operacionais (JOURAVLEV, 2001B). Consequentemente, esse é mais um fator que dificulta os investimentos para o setor e obriga que o marco regulatório ofereça garantias e estabilidade de regras suficientemente claras para os investidores.

A universalidade do atendimento, relacionada ao caráter essencial da prestação dos serviços, independe da capacidade de pagamento dos usuários. Dessa forma, o poder de monopólio se contrapõe ao caráter essencial dos serviços e à sua demanda inelástica, tornando a regulação fundamental para garantir o equilíbrio entre produtores e consumidores (FARINA; AZEVEDO; PICCHETTI, 1997).

Segundo a teoria da regulação, as características apresentadas para o setor configuram situações de falhas de mercado como poder de monopólio, externalidades, bens públicos e assimetria de informação, o que justificaria a regulação do setor. Além disso, vários estudiosos reafirmam a necessidade de regulação setorial com a seguinte finalidade:

- gerar incentivos para práticas eficientes de gestão, expansão do produto e redução de tarifas (SEROA DA MOTTA, 2006);

- maximizar a qualidade dos serviços e alavancar investimentos com vistas à modernização e à universalização do setor (CONFORTO, 2000);

- favorecer a adoção de gestão profissional e a autonomia administrativa das empresas públicas, além de ampliar a participação privada no setor (PENA; ABICALIL, 1999);
- limitar a interferência política no setor mediante regras implementadas independentemente do ciclo eleitoral (TRÉMOLET; HUNT, 2006);

- garantir a universalização do setor e evitar que os usuários paguem excessivamente pelos serviços prestados (BRITTO, 2001).

Considerando o fato de que o setor de água e esgoto ainda é operado majoritariamente por empresas estatais, além da necessidade do atendimento às características do desenho regulatório, a regulação setorial deve enfatizar a divisão de atribuições entre poder concedente e regulador. Efetivamente, a regulação é mais complexa quando as duas partes, regulado e regulador, pertencem ao mesmo ente federado. Diante disso, podem acontecer conflitos de interesse, sendo necessário, além da garantia de atendimento aos princípios de independência e autonomia, que o desenho regulatório preveja mecanismos de transparência, prestação de contas e controle social, entre outros, sob riscos de inviabilizar o atendimento aos objetivos regulatórios.

\section{Conclusões}

Ao estudar os diferentes aspectos conceituais da regulação dos serviços de água e esgoto no Brasil, conclui-se, entre outros aspectos, que é preciso conhecer seus limites e potencialidades para se ter clareza da forma como essa atividade pode contribuir efetivamente 
para a melhoria e universalização da prestação dos serviços de água e esgoto. No país, onde esses serviços são questionados pelos desperdícios e alocação inadequada dos recursos, é de se esperar que a regulação, nos termos da lei $n^{\circ} 11.445 / 2007$, contribua diretamente para a introdução de mecanismos de eficiência, assegurando qualidade a preços mais acessíveis, além de maior eficácia das ações para a melhoria das condições de salubridade e bem-estar social.

Entretanto, após análise comparativa com outros setores de infraestrutura de redes, concluí-se que, em função das características físicas, econômicas e institucionais do setor de água e esgoto, é complexo o processo de estabelecimento efetivo dessa atividade conforme os princípios da lei. Por fim, considerando a urgência da implementação da lei n 11.445/2007 e a relevância da regulação para eficácia dessa legislação, entende-se que essa atividade é fundamental para o desenvolvimento do setor, devendo ser aplicada tanto a empresas públicas como privadas, com formato institucional que respeite as características físicas e econômicas do setor e as particularidades locais e regionais para que, dessa forma, garanta-se a prevalência do interesse público.

\section{Referências}

AGÊNCIA NACIONAL DE ENERGIA ELÉTRICA. Resolução ANEEL $n^{\circ} 24$, de 27 de janeiro de 2000. Estabelece as disposições relativas à continuidade da distribuição de energia elétrica às unidades consumidoras. Brasília: ANEEL, 2000.

AGÊNCIA NACIONAL DE TELECOMUNICAÇÕES. Plano geral de metas da qualidade para o serviço telefônico fixo comutado. Brasília: Anatel, 2003.

AGÊNCIA REGULADORA DE SERVIÇOS PÚBLICOS DELEGADOS DO ESTADO DO CEARÁ. Resolução ARCE nº 24, de 16 de agosto de 2001. Disciplina a qualidade da água e de esgotos na prestação dos serviços de abastecimento de água e esgotamento sanitário. Fortaleza, CE, 2001.

BRASIL. Decreto $n^{\circ}$ 24.643, de 10 de julho de 1934. Decreta o Código das Águas. Rio de Janeiro, RJ, 1934

BRITTO, A.L.N.P. A Regulação dos serviços de saneamento no Brasil: perspectiva histórica, contexto atual e novas exigências de uma regulação pública. In: ENCONTRO NACIONAL DA ANPUR, 9, 2001, Rio de Janeiro. Anais... Rio de Janeiro: ANPUR, 2001. p. 1080-93.

CONFORTO, G. A regulação e a titularidade dos serviços de abastecimento de água e esgotamento sanitário no Brasil. Revista de Administração Pública, Rio de Janeiro, v. 34, n. 5, p. 165-80, set./out. 2000.

DI PIETRO, M.S.Z. Limites da função reguladora das agências diante do princípio da legalidade. In: DI PIETRO, M.S.Z. Direito regulatório: temas polêmicos. Belo Horizonte: Fórum, 2004. p. 19-50.

FARINA, E.M.M.Q.; AZEVEDO, P.F.; PICCHETTI, P. A reestruturação dos setores de infra-estrutura e a definição dos marcos regulatórios: princípios gerais, características e problemas. In: Ipea. Infra-estrutura: perspectivas de reorganização, regulação. Brasília: Ipea, 1997. v. 1, p. 43-80.

GALVÃO JUNIOR, A.C.; PAGANINI, W.S. Estado da arte da regulação da prestação dos serviços de água e esgoto no Brasil. In: CONGRESO DE LA ASOCIACIÓN INTERAMERICANA DE INGENIERÍA SANITARIA Y AMBIENTAL (AIDIS), 30, 2006, Punta del Leste, Uruguay. Anais... Punta del Leste: AIDIS, CD-ROM, 2006.
GALVÃO JUNIOR, A.C.; TUROLLA, F.A.; PAGANINI, W.S. Viabilidade da regulação subnacional dos serviços de abastecimento de água e esgotamento sanitário sob a lei 11.445/2007. Engenharia Sanitária e Ambiental, Rio de Janeiro, V. 13, n. 2, p. 134, abr./jun. 2008.

HUNT, E.K. História do pensamento econômico: uma perspectiva crítica. 2. ed. Rio de Janeiro: Elsevier, 2005.

HUTTON, G.; HALLER, L. Evaluation of the costs and benefits of water and sanitation Improvements at the global level. Genebra, Suíça: Organização Mundial da Saúde, 2004.

NÚCLEO DE PESQUISAS EM INFORMAÇÕES URBANAS DA UNIVERSIDADE DE SÃO PAULO. Fundamentos e proposta de ordenamento institucional. Brasília: Ministério do Planejamento e Orçamento. Secretaria de Política Urbana/lpea, 1995.

JOURAVLEV, A. Drinking water supply and sanitation services on the threshold of the XXI century. Santiago do Chile: Cepal, 2004.

Acceso a la información: una tarea pendiente para la regulación latinoamericana. Santiago do Chile: Cepal, 2003.

Regulación de la industria de agua potable: necesidades de información y regulación estructural. Santiago do Chile: Cepal, 2001A. v. 1.

Regulación de la industria de agua potable: regulación de las conductas. Santiago do Chile: Cepal, 2001B. v. 2.

MARQUES NETO, F.A. Agências reguladoras independentes: fundamentos e seu regime jurídico. Belo Horizonte: Fórum, 2005.

MOITA, R.M.S. Regulação por incentivos: a universalização dos serviços de saneamento básico. Dissertação (Mestrado em Economia) - Faculdade de Economia, Administração e Contabilidade, USP, São Paulo, 2000

NASCIMENTO, N.O.; HELLER, L. Ciência, tecnologia e inovação na interface entre as áreas de recursos hídricos e saneamento. Engenharia Sanitária e Ambiental, Rio de Janeiro, v. 10, n. 1, p. 36-48, jan./mar. 2005. 
ORGANIZAÇÃO MUNDIAL DA SAÚDE. The world health report 2007: a safer future: global public health security in the $21^{\text {st }}$ century. Genebra, Suécia, 2007.

PENA, D.S.; ABICALIL, M.T. Saneamento: os desafios do setor e a política de saneamento. In: Ipea. Infra-estrutura: perspectivas de reorganização, saneamento. Brasília: Ipea, 1999. p. 107-137.

PHILLIPS JUNIOR, C.F. The regulation of public utilities: theory and practice. Arlington, VA: Public Utilities Report, 1993.

PINHEIRO, A.C.; SADDI, J. Direito, economia e mercados. Rio de Janeiro: Elsevier, 2005.

SEROA DA MOTTA, R. As opções de marco regulatório de saneamento no Brasil. Plenarium, Brasília, n. 3, p. 100-116, set. 2006.

SEROA DA MOTTA, R.; MOREIRA, A. Efficiency and regulation in the sanitation sector in Brazil. Utilities Policy, v. 14, n. 3, p. 185-195, set. 2006.

SILVA, R.T. A regulação e o controle público da infra-estrutura e dos serviços urbanos no Brasil. In: DEÁK, C.; SCHIFFER, S.R. (Org.). O processo de urbanização no Brasil. São Paulo: Edusp, 2004. p. 261-312.
Público e privado na oferta de infra-estrutura urbana no Brasil. In: Anuário Gedim 2002 (Cidades, serviços e cidadania). Programa Interdisciplinar Globalização Econômica e Direitos no Mercosul (Gedim), Unesco/MOST. Rio de Janeiro: Lúmen Júris, 2002. p. 53112.

TEIXEIRA, J.C.; PUNGIRUM, M.E.M.C. Análise da associação entre saneamento e saúde nos países da América Latina e do Caribe, empregando dados secundários do banco de dados da Organização Pan-Americana de Saúde - OPAS. Revista Brasileira de Epidemiologia, São Paulo, v. 8, n. 4, p. 365-76, 2005.

TRÉMOLET, S.; HUNT, C. Taking account of the poor in water sector regulation. Washington, DC: World Bank, 2006

TUROLLA, F.A.; OHIRA, T.H. Saneamento básico: experiência internacional e avaliação de propostas para o Brasil. São Paulo: CNI, 2006

VARGAS, M.C.; LEME, A.; LIMA, R. State, market and utilities provision: economic theory perspectives. Oxford: Prinwass, 2002.

VISCUSI, Economics of regulation and antitrust. 4. ed. Cambridge: MIT Press, 2005 